\title{
Primary Hydatid Cyst of Vastus Lateralis Muscle
}

\author{
Cenk Aypak ${ }^{\mathrm{a}, \mathrm{e}}$, Adalet Altunsoy ${ }^{\mathrm{b}}$, Erdal Kaya ${ }^{\mathrm{c}}$, Pelin Yildiz ${ }^{\mathrm{d}}$
}

\begin{abstract}
Musculoskeletal system is rarely involved by hydatid cyst. A 42-year-old man was diagnosed as having a cystic mass within right thigh. Preoperative magnetic resonance imaging suggested an unusual location of hydatid disease, although serology was negative. A gray-white coloured cyst within right vastus lateralis muscle was enucleated during surgery. Histopathology confirmed the diagnosis. This case underlies that hydatid disease should be kept in mind in the differential diagnosis of any soft tissue mass especially in regions where it is endemic.
\end{abstract}

Keywords: Hydatid cyst; Vastus lateralis; Albendazole

\section{Introduction}

Hydatid disease is produced by the larval stage of the Echinococcus granulosus. It is endemic in many Mediterranean countries, the Middle East, South America, Australia and New Zealand Africa [1]. Approximately $70 \%$ of hydatid cysts are located in the liver [2]. Isolated musculoskeletal system involvement is very uncommon.

Manuscript accepted for publication August 10, 2011

a Department of Family Medicine, Gevas Hospital, 65110, Van, Turkey

${ }^{b}$ Department of Clinical Microbiology and Infectious Disease, Van

Training and Research Hospital, 65100, Van, Turkey

${ }^{c}$ Department of Orthopaedic Surgery and Traumatology, Van Training and Research Hospital, 65100, Van, Turkey

dDepartment of Pathology, Van Training and Research Hospital, 65100, Van, Turkey

e Corresponding author: Cenk Aypak, Department of Family Medicine, Gevas Hospital, 65110, Van, Turkey. Email: cenkaypak@yahoo.com

doi:10.4021/jmc273w
We report here an unusual case of an isolated hydatid cyst in right vastus lateralis muscle.

\section{Case Report}

A 42-year-old man from eastern Turkey presented with complaints of intermittent pain and swelling in his right thigh for eight months duration. He had no other complaints. The physical examination revealed a $5 / 6 \mathrm{~cm}$, round, palpable smooth mass in subcutaneous tissue of the right upper thigh.

Laboratory results which include renal and liver function tests showed that a haemoglobin level, a total leukocyte count and differentiation, were in the normal range. An erythrocyte sedimentation rate of $6 \mathrm{~mm} / \mathrm{h}$ and C-reactive protein, $0.144 \mathrm{mg} / \mathrm{dL}$ (normal, $5 \mathrm{mg} / \mathrm{dL}$ ) was detected. ELISA test for cyst hydatid IgG was negative.

Ultrasonography revealed a cystic mass, $6 \times 4 \mathrm{~cm}$ in diameter in the lateral muscular plans which was compatible with a haematoma or an abscess. Magnetic resonance imag-

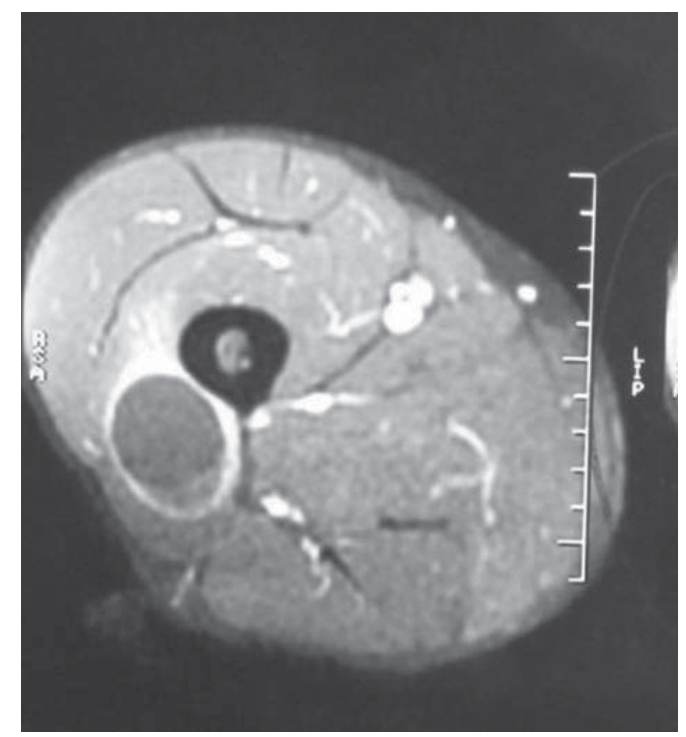

Figure 1. Contrast enhanced MR image shows that lesion is restricted to musculature. Note marked enhancement of cystic walls. 


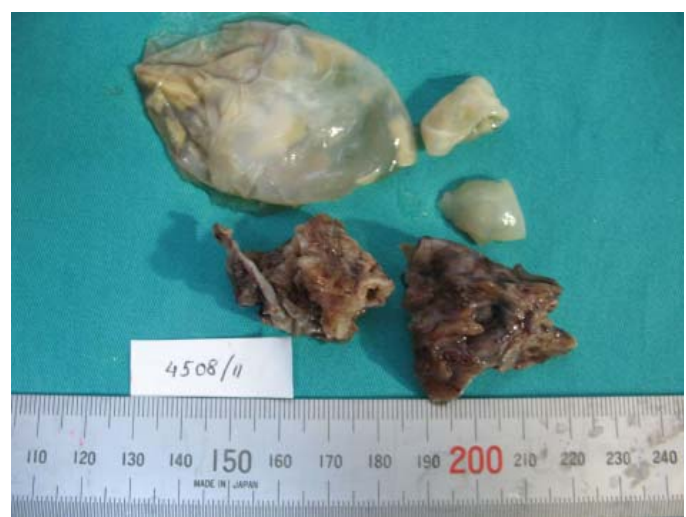

Figure 2. Echinococcal cysts excised from vastus lateralis Gross specimen.

ing (MRI) of the right upper thigh showed a cystic mass with multiple fine septa which was hypointense on T1-weighted images and hyperintense on T2-weighted images with an $4 \times$ $4 \times 4 \mathrm{~cm}$ dimension (Fig. 1). The chest and abdominal computed tomography examinations were normal.

The patient underwent an exploratory operation and the cyst was removed from the adjacent muscles. The appearence of the cyst (Fig. 2) suggested the diagnosis of hydatid disease which was confirmed on histopathology by the scolices of $E$. Granulosis with an adjacent laminated membrane (Fig. 3).

After the operation, $10 \mathrm{mg} / \mathrm{kg} /$ day of albendazole was given to the patient. He was discharged on the fifth postoperative day and came to his first control one month after the operation. The ultrasonography and MRI examinations, together with serologic tests, were normal. Albendazole therapy was administered for two months postoperatively.

\section{Discussion}

Although some authors report an incidence of musculoskeletal echinococcosis including involvement of subcutaneous tissue as $0.5-4.7 \%$ among all cases of hydatid disease [3], this statement is not clear because musculoskeletal cyst hydatid disease is a rare clinical condition even in the region where this zoonosis is endemic. It has been hypothesized that the reason for rarity of primary muscle localization could be due to bypassing through precapillary anastomosis (between pre and post parenchyma circulation) in liver [4]. Though the muscle environment is not favourable for hydatid cysts the volume of the muscle mass and its excessive blood supply could explain the rare localization in the proximal muscles of the lower limbs.

Preoperative diagnosis of the musculoskeletal hydatid cyst is difficult. Routine laboratory investigations are of little help. The sensitivity of various serological tests used for hydatid disease varies from 64 to $87 \%$ [5]. Hydatid serology is only valuable when it is positive, negative serologic test

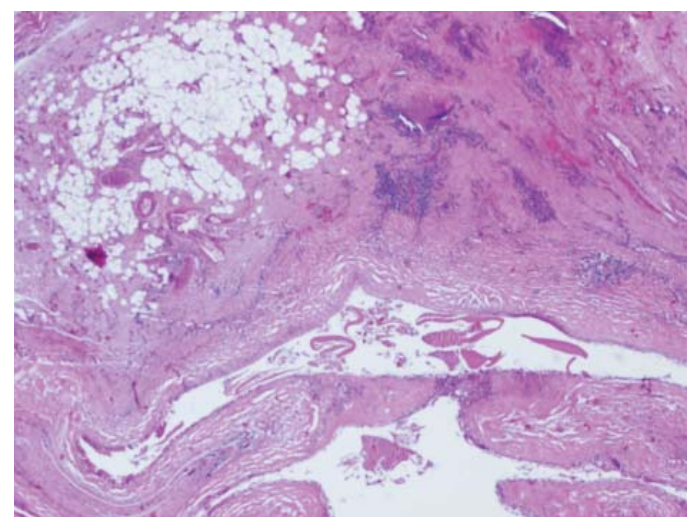

Figure 3. Cuticular membrane of the cyst hydatid and scolices in soft tissue (Hematoxylin-Eosin stain, x400).

does not exclude the diagnosis. If the cyst is not complicated, serology is less sensitive but it may be useful for controlling the recurrence of cyst. Magnetic Resonance Imaging is capable of adequately demonstrating most features of hydatid disease, with the exception of calcifications [5]. The gold standard test for diagnosis of hydatidosis is microscopic examination that shows the laminated membrane and scolices [1].

The recommended treatment of Echinococcus is complete excision of the cyst lining. During surgical intervention all precautions should be taken to prevent the recurrence of this disease.

This case illustrates that echinococcal disease should be considered in the differential diagnosis of every cystic mass in any anatomic location, especially when they occur in areas where the disease is endemic.

\section{Conflict of Interest}

None

\section{Grant Support}

None

\section{References}

1. Milicevic MN. Hydatid disease. In, Blumgart LH, Fong Y (eds). Surgery of the Liver and Biliary Tract. London, W.B. Saunders Company Ltd, 2000; 1167-1204.

2. Polat P, Kantarci M, Alper F, Suma S, Koruyucu MB, Okur A. Hydatid disease from head to toe. Radiographics. 2003;23(2):475-494; quiz 536-477.

3. Tacal T, Altinok D, Yildiz YT, Altinok G. Coexistence of intramuscular hydatid cyst and tapeworm. AJR Am J 
Roentgenol. 2000;174(2):575-576.

4. Chevalier X, Rhamouni A, Bretagne S, Martigny J, Larget-Piet B. Hydatid cyst of the subcutaneous tissue without other involvement: MR imaging features. AJR
Am J Roentgenol. 1994;163(3):645-646.

5. Echenique Elizondo MM, Amondarain Arratibel JA. Muscular hydatid disease. J Am Coll Surg. 2003;197(1):162. 